\title{
Numerical Simulation of the Churning Power Losses in the Automotive Hypoid Gear Reducer
}

\author{
Lin Zou, Mingya Du, Bing Jia, Jinli Xu, Liangshun Ren \\ School of Mechanical and Electronic Engineering, Wuhan University of Technology, Wuhan, China \\ Email: xuj11996@163.com
}

How to cite this paper: Zou, L., Du, M.Y., Jia, B., Xu, J.L. and Ren, L.S. (2018) Numerical Simulation of the Churning Power Losses in the Automotive Hypoid Gear Reducer. Journal of Applied Mathematics and Physics, 6, 1951-1956.

https://doi.org/10.4236/jamp.2018.69166

Received: June 20, 2018

Accepted: September 23, 2018

Published: September 30, 2018

\begin{abstract}
Improving vehicle transmission efficiency and reducing vehicle fuel consumption is currently one of the main objectives in the automotive field. Reducing gear churning power losses has significant influence on the decreasing vehicle fuel consumption. Based on the two phase flow theory, a $2 \mathrm{D}$ two-phase model of the simplified hypoid gear is established to predict the churning losses in different conditions, the VOF method is introduced to track the volume fraction of the free surface, a standard $k-\varepsilon$ model is also built to calculate complex turbulence. The oil distributions at the different rotational speed, the different immersion depth and the different viscosity as well as the churning losses of the hypoid gear are obtained and discussed in detail. In general, the churning power losses increase with the increase of the speed, the immersion depth and the viscosity, while the rotational speed shows the greatest influence on the churning losses. It is hoped that this investigation will be helpful in automotive industry applications.
\end{abstract}

\section{Keywords}

Churning Power Loss, Two Phases Flow, VOF Method, Hypoid Gear

\section{Introduction}

The internal transmission efficiency of the rear axle of a car directly affects the oil consumption of the whole vehicle. The gears and bearings, as the main components of the rear axle, play a key impact on the transmission efficiency of the rear axle. It is critical to figure out the mechanism of its efficiency losses to reduce the oil consumption of the whole vehicle.

In the last years, the churning losses of the gears have been the subject of extensive numerical and experimental investigations. Concli \& Gorla computationally and experimentally analyzed the churning power losses in an industrial 
planetary speed reducers and point out that the VOF method could provide more information on the physical phenomena than any experimental measurement [1]. And then they developed a new approach to predict churning power losses of ordinary gears [2]. Kodela et al. proposed a CFD method to estimate the splash loss for the complete manual transmission gear box at the different operating conditions such as the rotational speed, the temperature and the oil level [3]. Liu et al. numerically investigated the oil distribution and the churning loss of a single-stage gearbox by the finite volume CFD method, and showed that the turbulence of oil increased with the increase of the rotational speed [4]. Wang et al. numerically investigated the churning losses of the spur gear, but found out that there are big differences between simulation values and theoretical calculation [5]. Concli \& Gorla further pointed out that the power losses were not directly decreased with the increase of the temperature, and an optimal temperature existed [6].

The above literatures mostly pay attention to investigating the churning losses of the spur gear. However, less investigation on the churning losses of the hypoid gears is discussed. In the present study, the oil distribution of the hypoid gear at the different conditions and the influencing factors of the churning losses such as the speed, the immersion depth and the viscosity are obtained and discussed. It is hoped that this investigation will be helpful for the deepening of our understanding on the oil consumption of the whole vehicle.

\section{Governing Equations and Numerical Method}

The numerical method stated in this paper depends on the solution of two governing equations that mathematically represent the conservation laws of mass and momentum [7]:

$$
\begin{gathered}
\frac{\partial u_{i}}{\partial x_{i}}=0 \\
\frac{\partial u_{i}}{\partial t}+\frac{\partial\left(u_{i} u_{j}\right)}{\partial x_{i}}=-\frac{1}{\rho} \frac{\partial p}{\partial x_{i}}+\eta \frac{\partial}{\partial x_{i}}\left(\frac{\partial u_{j}}{\partial x_{i}}+\frac{\partial u_{i}}{\partial x_{j}}\right)+f_{i}
\end{gathered}
$$

where $u_{i}$ is velocity in the $x_{i}$ direction. Where $p$ is pressure, $\rho$ is mixture density, $\eta$ is the mixture viscosity, $u_{i}$ is velocity in the $y_{i}$ direction, $f_{i}$ is acceleration vector in $x_{i}$ direction. The behavior of a transient incompressible flow is described by these basic equations.

The presence of more than one phase implies the need of additional equations. VOF method has been widely used to track the interface of two phases. Thus, a transportation equation for the volume fraction $\alpha$ is introduced [8]:

$$
\frac{\partial \alpha}{\partial t}+\frac{\partial\left(\alpha u_{i}\right)}{\partial x_{i}}=0
$$

In the two-phase flow system, the mixture properties of density and viscosity can be given by the volume weighted average of two liquids as: 


$$
\begin{gathered}
\rho=\alpha \rho_{\text {oil }}+(1-\alpha) \rho_{\text {air }} \\
\eta=\alpha \eta_{\text {oil }}+(1-\alpha) \eta_{\text {air }}
\end{gathered}
$$

where $\rho_{\text {oil }}$ is density of oil, $\rho_{\text {air }}$ is density of air, $\eta_{o i l}$ is viscosity of oil, $\eta_{a i r}$ is viscosity of air. In order to obtain the solution of equations, the standard $k-\varepsilon$ turbulence model is applied to calculate the complex turbulent problems with high Reynolds number. The turbulence equation can be written as [9] [10]:

$$
\begin{gathered}
\rho \frac{\partial\left(k u_{i}\right)}{\partial x_{i}}=\frac{\partial}{\partial x_{i}}\left[\left(\eta+\frac{\eta_{t}}{\sigma_{k}}\right) \frac{\partial k}{\partial x_{i}}\right]+\rho(S-\varepsilon) \\
\rho \frac{\partial\left(\varepsilon u_{i}\right)}{\partial x_{i}}=\frac{\partial}{\partial x_{i}}\left[\left(\eta+\frac{\eta_{t}}{\sigma_{k}}\right) \frac{\partial \varepsilon}{\partial x_{i}}\right]+\rho \frac{\varepsilon}{k}\left(C_{1} S-C_{2} \varepsilon\right)
\end{gathered}
$$

where,

$$
\begin{gathered}
\eta_{t}=\rho C_{\eta} \frac{k^{2}}{\varepsilon} \\
S=\frac{\eta_{t}}{\rho}\left(\frac{\partial u_{i}}{\partial x_{j}}+\frac{\partial u_{j}}{\partial u_{i}}\right) \frac{\partial u_{i}}{\partial x_{j}} \\
C_{\eta}=0.09, \quad C_{1}=1.44, C_{2}=1.92, \sigma_{k}=1.0, \sigma_{\varepsilon}=1.3 .
\end{gathered}
$$

\section{Geometrical Model and Boundary Conditions}

In order to reduce the number of cells and save time, it's necessary to simplify the geometrical model of the hypoid gear (Figure 1). The whole model has been discretized with tetrahedral mesh (Figure 2). During the simulation, the meshes of the hypoid gear rotates in the closed domain at the predefined rotational speed.

Table 1 shows the combinations of specific parameters for each simulation.

\begin{tabular}{|c|c|c|c|c|c|c|c|}
\hline Oil type & & & & & 75W90 & $85 \mathrm{~W} 90$ & $85 \mathrm{~W} 140$ \\
\hline Immersion depth (mm) & $0.5 \mathrm{~h}$ & $1.0 \mathrm{~h}$ & $1.5 \mathrm{~h}$ & $2 \mathrm{~h}$ & & $1.5 \mathrm{~h}$ & \\
\hline
\end{tabular}
These are respectively simulated at $100 \mathrm{rpm}, 400 \mathrm{rpm}$ and $700 \mathrm{rpm}$, and $\mathrm{h}$ represents height of a tooth. Table 2 shows the kinematic viscosity corresponding to each oil type. These are all GL-5 type at $40^{\circ} \mathrm{C}$.

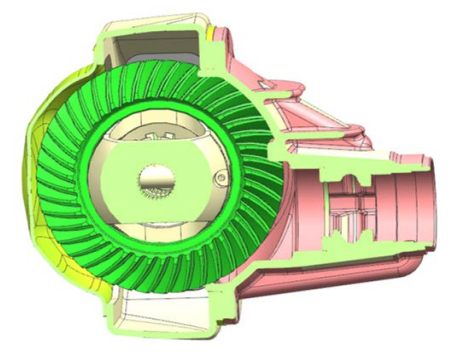

Figure 1. Geometrical model of the hypoid gear.

Table 1. Specific parameters of each simulation at the different ratational speed. 


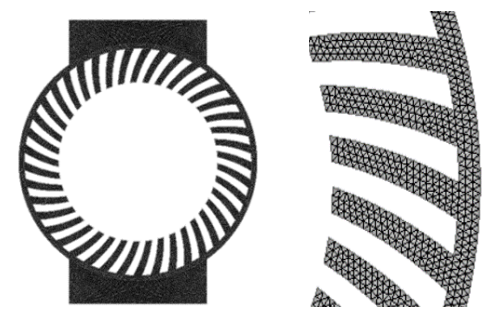

Figure 2. Grid model of the hypoid gear.

Table 2. Viscosity corresponding to oil type.

\begin{tabular}{ccccc}
\hline Oil type & $75 \mathrm{~W} 80$ & $75 \mathrm{~W} 90$ & $85 \mathrm{~W} 90$ & $85 \mathrm{~W} 140$ \\
\hline Kinematic viscosity at $40^{\circ} \mathrm{C}\left(\mathrm{m}^{2} / \mathrm{s}\right)$ & 59.07 & 82.88 & 248 & 284.3 \\
\hline
\end{tabular}

\section{Results and Discussion}

Figure 3 shows that the power loss increases with the immersion depth. Decreasing the immersion depth from $2.0 \mathrm{~h}$ to $1.5 \mathrm{~h}$, the power increases about only 50 watts under the same speed. The relation between the immersion depth and the power loss is relatively weak. Figure 4 shows the effect of the viscosity on the power loss. While the viscosity increases from $59.07 \mathrm{~mm}^{2} / \mathrm{s}$ to $82.88 \mathrm{~m}^{2} / \mathrm{s}$, the power loss increases 8.4 watts at $100 \mathrm{rpm}, 21.4$ watts at $400 \mathrm{rpm}$ and 991.8 watts at $700 \mathrm{rpm}$. These results show that the rotational speed has impact on effect extent of the viscosity on churning losses. Furthermore, oil type named GL-5 75W80 have minimum effect on power loss. The diagrams show the impact of the rotational speed on power loss. It can be clearly seen that the power approximately enhances with $90 \%$ while the rotational speed is reduced by 300 $\mathrm{rpm}$. Therefore, the rotational speed has the greatest influence on the churning loss. Figure 5 shows contours of volume fraction for the oil distribution at the different rotational speed. The gear churns more oil with high speed, which results in easily generating larger churning torque. This explains the influence of rotational speed on power loss is maximum.

\section{Conclusions}

Based on two-phase flow, the VOF method and the standard k- $\varepsilon$ model, a new simplified 2D model is established. The oil distributions and the churning power losses of the hypoid gear at the different working conditions with the rotational speed of $100 \mathrm{rpm}, 400 \mathrm{rpm}$ and $700 \mathrm{rmp}$ at the immersion depth from $0.5 \mathrm{~h}$ to 2 $\mathrm{h}$ were numerically investigated.

In general, the churning power losses increased with the increase of the rotational speed and the immersion depth as well as the viscosity, which the rotational speed has the greatest influence on the churning loss. Minimum effect on the power loss is oil type named GL-5 75W80. The difference reaches tens of watts between $100 \mathrm{rpm}$ and $400 \mathrm{rpm}$ but runs up to hundreds of watts at the range of $400 \mathrm{rpm}$ to $700 \mathrm{rpm}$. The turbulence of oil increases with the rotational speed, which causes higher oil power loss. 


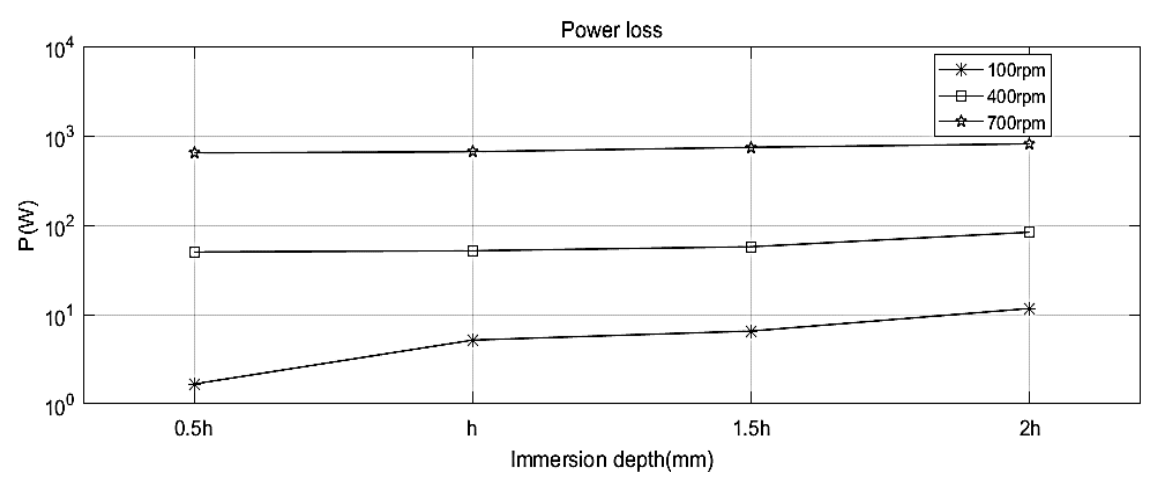

Figure 3. The effect of the immersion depth on power loss at three different rotational speed.

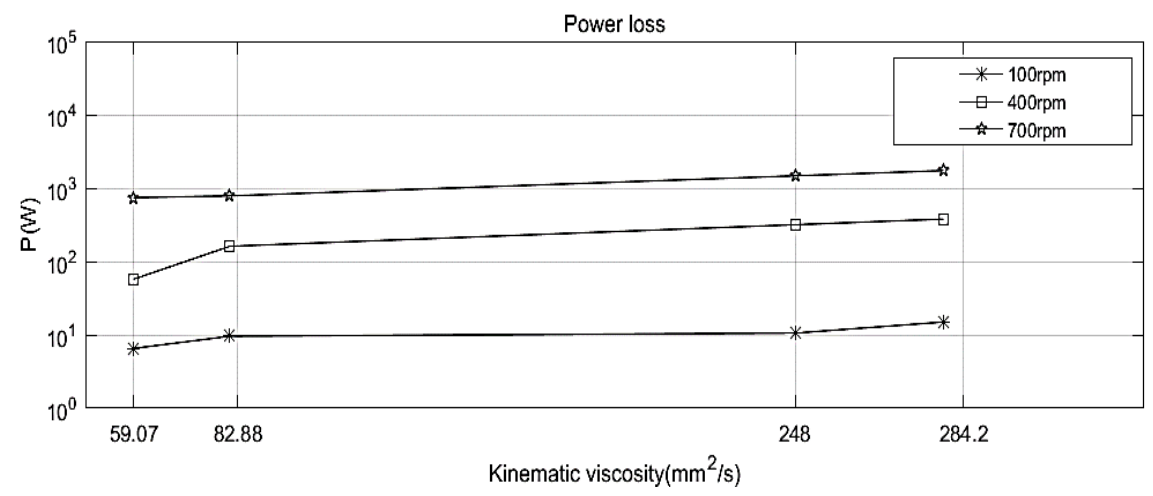

Figure 4. The effect of the viscosity on the power loss at three different rotational speed.

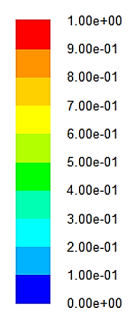

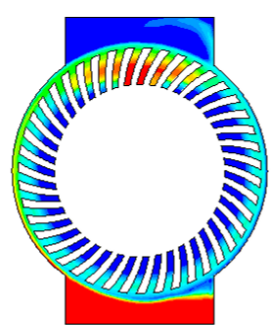

(a)

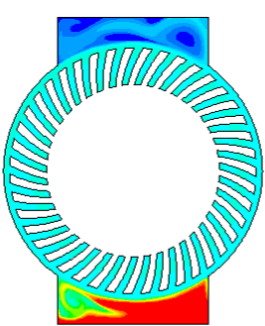

(b)

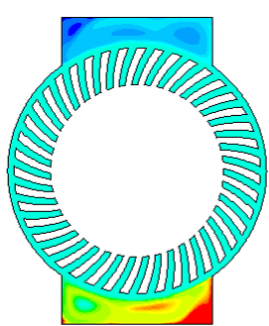

(c)

Figure 5. (a) Contours of volume fraction for the oil phase at $100 \mathrm{rpm}$; (b) Contours of volume fraction for the oil phase at $400 \mathrm{rpm}$; (c) Contours of volume fraction for the oil phase at $700 \mathrm{rpm}$.

However, the lower speed and the viscosity as well as the immersion depth have influence on gear lubrication and meshing. Thus, the meshing loss of gear transmission system and the impact of lubrication on power loss will be investigated in further studies.

\section{Acknowledgements}

The authors wish to thank the Liuzhou Science and Technology Bureau of Guangxi Province, China, for its support through Liuzhou science and technology research key project (Grant No. 2017AA10102). 


\section{Conflicts of Interest}

The authors declare no conflicts of interest regarding the publication of this paper.

\section{References}

[1] Concli, F. and Gorla, C. (2011) Computational and Experimental Analysis of the Churning Power Losses in an Industrial Planetary Speed Reducers. Proceedings of the 9 th International Conference on Advances in Fluid Mechanics, Split, 26-28 June 2012, 287-298.

[2] Concli, F., Gorla, C., Della Torre A. and Montenegro, G. (2015) Churning Power Losses of Ordinary Gears: A New Approach Based on the Internal Fluid Dynamics Simulations. Lubrication Science, 27, 313-326. https://doi.org/10.1002/1s.1280

[3] Kodela, C., Kraetschmer, M. and Basa, S. (2015) Churning Loss Estimation for Manual Transmission Gear Box Using CFD. SAE International Journal of Passenger Cars-Mechanical Systems, 8.

[4] Liu, H., Jurkschat, T., Lohner, T. and Stahl, K. (2017) Determination of Oil Distribution and Churning Power Loss of Gearboxes by Finite Volume CFD Method. Tribology International, 109, 346-354. https://doi.org/10.1016/j.triboint.2016.12.042

[5] Wang, B., Liu, L.J. and Wang, P. (2014) Simulation of Churning Losses in Geared Box. Applied Mechanics and Materials, 703, 241-244. https://doi.org/10.4028/www.scientific.net/AMM.703.241

[6] Concli, F. and Gorla, C. (2013) Influence of Lubricant Temperature, Lubricant Level and Rotational Speed on the Churning Power Loss in an Industrial Planetary Speed Reducer: Computational and Experimental Study. International Journal of Computational Methods and Experimental Measurements, 1, 353-366. https://doi.org/10.2495/CMEM-V1-N4-353-366

[7] Gao, D., Morley, N.B. and Dhir, V. (2003) Numerical Simulation of Wavy Falling Film Flow Using VOF Method. Journal of Computational Physics, 192, 624-642. https://doi.org/10.1016/j.jcp.2003.07.013

[8] Theodorakakos, A. and Bergeles, G. (2004) Simulation of Sharp Gas-Liquid Interface Using VOF Method and Adaptive Grid Local Refinement around the Interface. International Journal for Numerical Methods in Fluids, 45, 421-439. https://doi.org/10.1002/fld.706

[9] Hou, Q. and Zou, Z. (2006) Comparison between Standard and Renormalization Group k-.EPSILON. Models in Numerical Simulation of Swirling Flow Tundish. Isij International, 45, 325-330. https://doi.org/10.2355/isijinternational.45.325

[10] Sinha, K. and Balasridhar, S.J. (2013) Comparison between Standard and Renormalization Group k-.EPSILON. Models in Numerical Simulation of Swirling Flow Tundish. AIAA Journal, 51, 1872-1882. https://doi.org/10.2514/1.J052289 